\section{Midbrain vasculitic aneurysms}

Hyung-Min Kwon, MD, Jae-Kyu Roh, MD, PhD, Gregory Youngnam Chang, LTC, MC, Seoul, Korea

This 16-year-old girl had a muscle biopsy demonstrating vasculitis seven years ago when she presented with weakness and Raynaud's phenomenon (figure, B). Aside from occasional unexplained abdominal pain and chronic anemia, she had been well until one year ago, when she presented with a transient right body numbness and left ptosis. Five days of left body numbness, vertigo, and diplopia prompted readmission. Examination revealed limited upgaze, right internuclear ophthalmoplegia, and a clumsy left upper extremity. Laboratory markers for autoimmune diseases and a transesophageal echocardiogram were normal. Systemic vascular screening confirmed multiple aneurysms in the gastrointestinal and renal arteries.

The opinions or assertions contained herein are the private views of the author (GYC) and are not to be construed as representing the views of the Department of Defense, or the Department of the Army.

Address correspondence and reprint requests to Dr. Gregory Youngnam Chang, HHC 121st General Hospital, Box 227, APO AP 96205-0017, USA; e-mail: gychang@operamail.com
Neuro Images

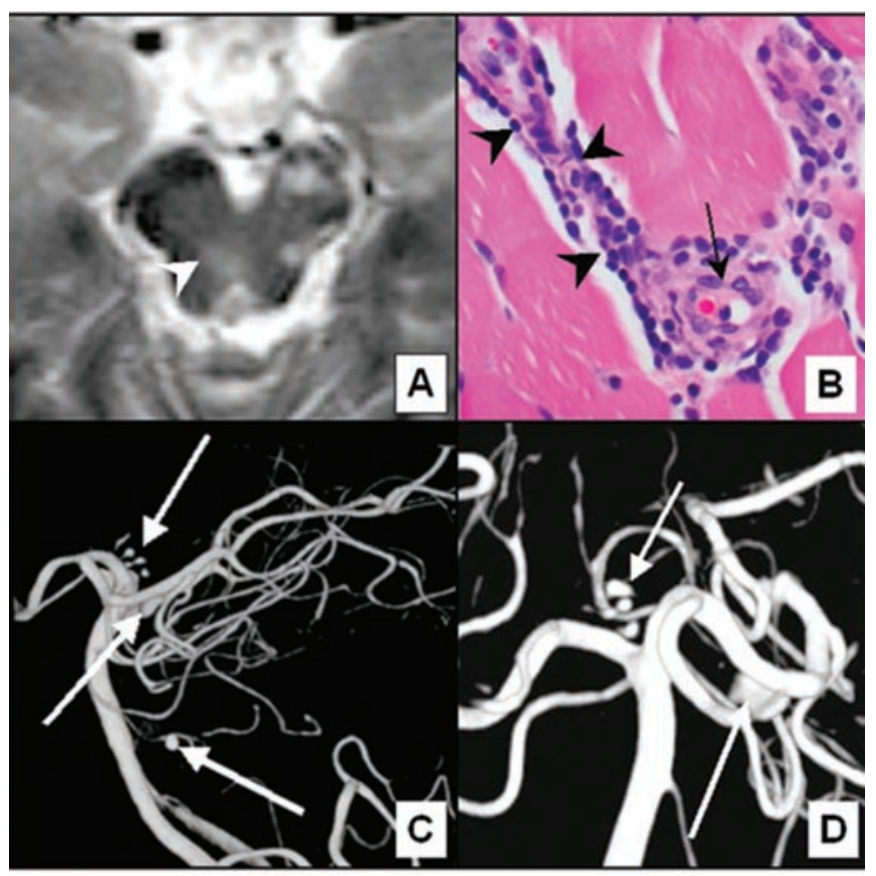

Figure. Bilateral midbrain infarctions. White arrowhead points to the most recent stroke (A). Muscle biopsy shows arteriolar lymphocytic infiltration surrounding the lumen (arrow) and along the vessel wall (arrowhead) (B). Lateral view, (C), Rotational angiography with three-dimensional reconstruction showing cluster of aneurysms near the top of the basilar artery (top white arrow) and two other single aneurysms, (anterio-posterior view) (D). 


\title{
Neurology
}

\author{
Midbrain vasculitic aneurysms \\ Hyung-Min Kwon, Jae-Kyu Roh and Gregory Youngnam Chang \\ Neurology 2004;63;145 \\ DOI 10.1212/01.WNL.0000132960.75111.FF
}

This information is current as of July 12, 2004

\section{Updated Information \&}

Services

Permissions \& Licensing

Reprints including high resolution figures, can be found at:

http://n.neurology.org/content/63/1/145.full

Information about reproducing this article in parts (figures,tables) or in its entirety can be found online at:

http://www.neurology.org/about/about_the_journal\#permissions

Information about ordering reprints can be found online:

http://n.neurology.org/subscribers/advertise

Neurology ${ }^{\circledR}$ is the official journal of the American Academy of Neurology. Published continuously since 1951, it is now a weekly with 48 issues per year. Copyright . All rights reserved. Print ISSN: 0028-3878. Online ISSN: 1526-632X.

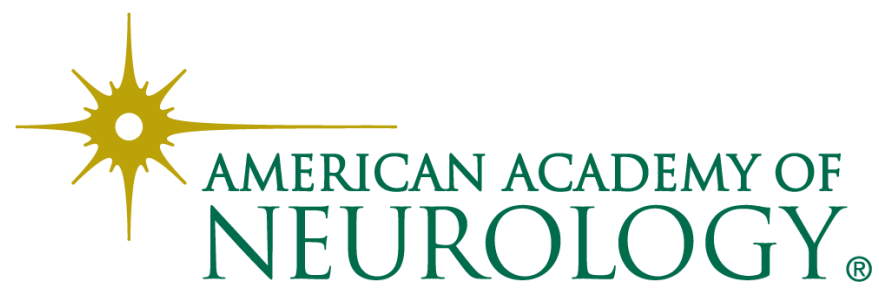

